\title{
Saline infusion sonography in evaluation of uterine cavity abnormalities in infertility: a comparative study
}

\author{
Anita Sitimani $^{1}$, Indu Chawla ${ }^{1}$, Poonam Vohra ${ }^{2}$ \\ ${ }^{1}$ Department of Obstetrics and Gynaecology, ${ }^{2}$ Department of Radio Diagnosis PGIMER and Dr. RML Hospital, New
} Delhi-110021, India

Received: 29 June 2016

Accepted: 05 August 2016

*Correspondence:

Dr. Indu Chawla,

E-mail: induchawla2009@gmail.com

Copyright: ( $\odot$ the author(s), publisher and licensee Medip Academy. This is an open-access article distributed under the terms of the Creative Commons Attribution Non-Commercial License, which permits unrestricted non-commercial use, distribution, and reproduction in any medium, provided the original work is properly cited.

\section{ABSTRACT}

Background: Infertility is defined as one year of unprotected intercourse without pregnancy. Female factor is responsible for $40-50 \%$ of cases of infertility. Uterine pathologies are the cause of infertility in as many as $15 \%$ of couples seeking treatment. The objective of this study was to evaluate the accuracy of trans-vaginal sonography (TVS) and saline infusion sonography (SIS) for detection of uterine cavity abnormalities in patients of infertility taking hysteroscopy as gold standard.

Methods: A prospective comparative study was done in 60 patients of infertility. Patients were selected from gynaecology OPD of a tertiary care hospital. Patient selected underwent TVS and SIS followed by hysteroscopy for presence of uterine cavity abnormalities. The presence of uterine cavity abnormality and its type (endometrial polyp, submucous myoma, intrauterine synechiae or any other) was noted. The results of TVS and SIS were compared with hysteroscopy.

Results: In 60 infertile patients, hysteroscopy revealed intrauterine pathology in 22 patients (36.7\%). Among them eight had endometrial polyp and another eight patients had intrauterine synechiae. Submucous myoma was detected in five patients and one patient had thin endometrium. SIS detected eight out of 22 uterine cavity abnormalities indicating sensitivity, specificity, positive predictive value (PPV) and negative predictive value (NPV) of $36.4 \%$, $100 \%, 100 \%$ and $73.1 \%$ respectively. In comparison TVS showed abnormalities in six patients only and thus had sensitivity, specificity, PPV and NPV of $27.35 \%, 100 \%, 100 \%$ and $70.4 \%$ respectively. Sensitivity of SIS for specific lesion was least for intrauterine synechiae (12.5\%) and maximum for submucous myoma (60\%).

Conclusions: The sensitivity of both TVS and SIS for detection of uterine cavity abnormalities in patients of infertility was low in the present study and they cannot be recommended as replacement for hysteroscopy.

Keywords: Hysteroscopy, Infertility, Saline infusion sonography, Sensitivity, Specificity

\section{INTRODUCTION}

Infertility is defined as one year of unprotected intercourse without pregnancy. Female factor is responsible for $40-50 \%$ of cases of infertility. Uterine pathologies are the cause of infertility in as many as $15 \%$ of couples seeking treatment. ${ }^{1}$ Uterine abnormalities that have been implicated in infertility include endometrial polyp, sub mucous myoma, intrauterine adhesions, and mullerian anomalies. Hence the evaluation of shape and regularity of uterine cavity is one of the basic steps in work up of infertile patients. ${ }^{2}$

Various diagnostic modalities available to evaluate uterine cavity are hysterosalpingography (HSG), saline infusion sonography (SIS), trans-vaginal sonography (TVS) and hysteroscopy. Hysterosalpingography suffers from the drawback that it has low specificity and false 
negative rate of $10 \% .^{3}$ TVS, though simple and noninvasive, has limitation in evaluation of uterine cavity because uterine cavity is a virtual space. ${ }^{4}$ SIS, which involves instillation of saline into uterine cavity during scanning, improves the accuracy of TVS. The procedure does not require an anaesthetic and can be performed in outpatient clinic. SIS takes the advantage of saline as a negative contrast agent and also utilises the distension property of uterus thereby delineating the structural abnormalities of uterine cavity like submucous myoma, endometrial polyp, septate uterus and intrauterine synechiae. ${ }^{5}$

Hysteroscopy is considered gold standard for the diagnosis of uterine cavity pathology and it has been suggested that it should be part of basic infertility work up. ${ }^{-}$Diagnostic hysteroscopy is a highly specialized procedure requiring costly equipment and training to perform, besides being invasive with its inherent disadvantages. Hence, the study was undertaken to evaluate the accuracy of SIS and TVS in the diagnosis of intrauterine abnormalities in population of infertile patients taking hysteroscopy as the gold standard.

\section{METHODS}

This prospective study was conducted in the department of obstetrics and gynaecology and radiology, post graduate institute of medical education and research, Dr. Ram Manohar Lohia Hospital, New Delhi, from November 2012 to August 2013. Approval from hospital ethical committee was obtained prior to initiation of study. Patients who presented with infertility to gynaecology OPD were subjected to detailed clinical history and examination. Relevant investigations pertaining to infertility were done and patients with husband's semen being abnormal were not included in the study. Patients with active pelvic inflammatory disease, adnexal masses and cervical pathology were excluded from the study. Patients thus selected underwent TVS and SIS followed by hysteroscopy. A written informed consent was taken from all the patients. A single investigator (PV) performed TVS and SIS to eliminate inter-observer variation. One person (IC) performed all hysteroscopy procedures and the results of SIS were not known to her.

SIS was performed after cessation of menses no later than day 10. TVS was performed with Siemens Sonoline Adara $(7.5 \mathrm{MHz})$ by a senior ultrasonologist (PV) and endometrial thickness was measured and note made of any focal pathology. SIS was performed in the same sitting with the help of gynaecologists (AS). All patients were given tablet mefanemic acid $500 \mathrm{mg}$ half an hour prior to the procedure. Under all aseptic precautions a sterile Sims speculum was inserted in posterior fornix and anterior lip of cervix was held with valsellum. Foleys catheter number 8 was advanced through external os into endometrial cavity and balloon was inflated. The speculum was carefully removed and endo-vaginal probe was inserted beside the catheter. Under direct sonographic visualization balloon was gently pulled to occlude the internal os and $10-15 \mathrm{ml}$ of sterile saline was injected into the endometrial cavity, pushing the apposed walls of endometrium apart. Complete sonographic evaluation of endometrial cavity was performed in both coronal and sagittal planes. Endometrial thickness was measured by adding the anterior and posterior endometrial thickness excluding the anechoic part. The balloon was then deflated and evaluation of the lower uterine segment and endocervical region was performed. Results of TVS and SIS were expressed using the following criteria: normal finding (smooth endometrium with normal regular contour), endometrial polyp (hyperechogenic pedunculated lesion) and submucous myoma (lesion of mixed echogenicity disrupting the endometrial cavity). Intrauterine adhesions appeared as asymmetric dense echogenic lesions and hypo echoic areas within the cavity.

Hysteroscopy was performed with Hopkins II straight forward $5 \mathrm{~mm}$; 0 degree/30 degree telescope (Karl Storz, Germany) under paracervical anaesthesia within 4- 6 weeks of SIS in the postmenstrual phase by senior gynaecologists (IC). Normal saline was used as distension medium, at the pressure of 50-100 $\mathrm{mm}$ of $\mathrm{Hg}$. Three hours prior to procedure tablet misoprostol was inserted by vaginal route. On insertion of hysteroscope endocervical canal was visualized followed by endometrial cavity. The findings were categorized as normal uterine cavity, endometrial polyp, submucous myoma and intrauterine adhesions .While performing hysteroscopy, polypectomy for polyp and adhesiolysis were done in the same sitting whenever required.

Statistical analysis was performed by SPSS programme for windows version 17. Continuous variables were presented as mean \pm SD and categorical variables were presented as absolute numbers and percentage. Categorical variables were analyzed using either the chi square test or Fisher's exact test. Sensitivity, specificity, PPV, NPV was calculated to analyze the diagnostic accuracy of SIS and TVS with the gold standard hysteroscopy.

\section{RESULTS}

Total of 60 patients who could complete both the procedures i.e. SIS and hysteroscopy were included in the study. In three patients adequate distension could not be achieved on SIS and in two patients hysteroscope could not be introduced due to tight stenosis of cervical canal, hence were not included in the study. Out of 60 patients, $34(56.76 \%)$ had primary infertility and $26(43.3 \%)$ had secondary infertility. Forty nine patients $(81.6 \%)$ were in the age group of $21-30$ years, nine $(15 \%)$ were in the age group 31-40 years, and two patients (3.3\%) were less than 20 years of age. Mean duration of complaint was 3.88 years with a standard deviation of \pm 2.37 . 
On hysteroscopy, 38 patients $(63.3 \%)$ had normal endometrial cavity and $22(36.7 \%)$ were diagnosed with intra-cavity abnormalities. Endometrial polyp was observed in eight $(13.3 \%)$, synechiae in another eight $(13.3 \%)$, submucous myoma in five $(8.3 \%)$ and thin endometrium in one patient $(1.7 \%)$ (Table 1$)$.

Table 1: Findings at TVS, SIS, and hysteroscopy in patients with infertility $(n=60)$.

\begin{tabular}{|llll|}
\hline Findings & $\begin{array}{l}\text { TVS } \\
(\%)\end{array}$ & $\begin{array}{l}\text { SIS } \\
(\%)\end{array}$ & $\begin{array}{l}\text { Hysteroscopy } \\
(\%)\end{array}$ \\
\hline Normal cavity & 90 & 86.7 & 63.3 \\
\hline $\begin{array}{l}\text { Uterine cavity } \\
\text { abnormalities }\end{array}$ & 10 & 13.3 & 36.7 \\
\hline Endometrial Polyp & 1.7 & 5 & 13.3 \\
\hline Submucous myoma & 0 & 5 & 8.3 \\
\hline Thin endometrium & 6.66 & 1.7 & 1.7 \\
\hline Synechiae & 0 & 1.7 & 13.3 \\
\hline Endometrial hyperplasia & 1.7 & 0 & 0 \\
\hline
\end{tabular}

Table 2: Comparison of findings at TVS, SIS and hysteroscopy $(n=60)$.

\begin{tabular}{|c|c|c|}
\hline & \multicolumn{2}{|c|}{ Hysteroscopy findings } \\
\hline & Abnormal $^{\text {a }}(\mathrm{n}=22)$ & Normal $(n=38)$ \\
\hline \multicolumn{3}{|l|}{ TVS } \\
\hline Abnormal (6) & 6 & 0 \\
\hline Normal (54) & 16 & 38 \\
\hline \multicolumn{3}{|l|}{ SIS } \\
\hline Abnormal (8) & 8 & 0 \\
\hline Normal (52) & 14 & 38 \\
\hline
\end{tabular}

At SIS, 52 patients $(86.7 \%)$ had normal endometrial cavity and eight $(13.3 \%)$ were diagnosed with uterine cavity abnormalities (Table 2). Endometrial polyp was seen in three $(5 \%)$, submucous myoma in another three
$(5 \%)$.Thin endometrium was detected in one $(1.66 \%)$ and intrauterine synechiae in one (1.66\%) (Table 1). SIS detected eight out of 22 patients with intra-cavity abnormality indicating sensitivity of $36.4 \%$. All the eight patients of abnormal findings on SIS were found to have abnormal hysteroscopic findings (specificity $=100 \%$ ). Hence, there were no false positive and 14 false negative giving PPV of $100 \%$ and NPV of $73.1 \%$ taking hysteroscopy as gold standard.

On TVS, 54 patients (90\%) had normal uterine cavity and only $6(10 \%)$ were diagnosed with uterine cavity abnormalities (Table 2). Endometrial polyp was seen in one $(1.7 \%)$, endometrial hyperplasia in one $(1.7 \%)$, and four patients $(6.66 \%)$ had thin endometrium (Table 1$)$. TVS allowed the detection of six of 22 patients with abnormal findings (sensitivity $=27.3 \%$ ) and all these patients were found to have some abnormality on hysteroscopy also (specificity $=100 \%$ ). There were no false positive but 16 false negative thus giving the overall positive predictive value (PPV) of $100 \%$ and negative predictive value (NPV) of $70.41 \%$.

Accuracy of SIS for diagnosis of individual abnormality was calculated. Eight patients were found to have endometrial polyp on hysteroscopy and SIS missed the diagnosis in six cases (sensitivity $=25 \%$ ). Out of three patients diagnosed to have endometrial polyp on SIS, hysteroscopy confirmed the diagnosis in two patients ( specificity $=66.6 \%)$. Submucous myoma was diagnosed in five patients on hysteroscopy and three could be correctly picked on SIS (sensitivity $=60 \%$ ). On hysteroscopy eight patients were found to have intrauterine adhesions i.e. synechiae. Five out of eight patients had mild synechiae. SIS picked only one of eight patients (sensitivity $=12.5 \%$ ). Out of remaining seven patients five were labelled as normal, one as thin endometrium and polyp each on SIS (Table 3).

Table 3: Comparison of SIS results with hysteroscopy $(n=60)$.

\begin{tabular}{|llllll|}
\hline SIS result & $\begin{array}{l}\text { Normal } \\
\text { endometrium }\end{array}$ & $\begin{array}{l}\text { Endometrial } \\
\text { polyp }\end{array}$ & $\begin{array}{l}\text { Hysteroscopic findings } \\
\text { Submucous } \\
\text { myoma }\end{array}$ & $\begin{array}{l}\text { Thin } \\
\text { endometrium }\end{array}$ & Synechiae \\
\hline Normal (52) & 38 & 6 & 2 & 1 & 5 \\
\hline Endometrial polyp (3) & 0 & 2 & 0 & 0 & 1 \\
\hline Submucous myoma (3) & 0 & 0 & 3 & 0 & 0 \\
\hline Thin endometrium (1) & 0 & 0 & 0 & 0 & 1 \\
\hline Synechiae (1) & 0 & 0 & 0 & 0 & 1 \\
\hline Total (60) & $\mathbf{3 8}$ & $\mathbf{8}$ & $\mathbf{5}$ & $\mathbf{1}$ & $\mathbf{8}$ \\
\hline
\end{tabular}

On SIS 52 patients were found to have normal endometrial cavity and hysteroscopy confirmed the findings in 38 , while six had endometrial polyp, two had submucous myoma and five patients had intrauterine adhesions and one patient had thin endometrium (Table $3)$. 
TVS showed normal uterine cavity in 54 cases and on hysteroscopy 38 cases had normal uterine cavity. Seven cases of endometrial polyp, four cases of submucous myoma and five cases of synechiae were missed by TVS (Table 4).

Table 4: Comparison of TVS results with hysteroscopy $(n=60)$.

\begin{tabular}{|c|c|c|c|c|c|}
\hline \multirow[t]{2}{*}{ TVS result } & \multicolumn{5}{|c|}{ Hysteroscopic findings } \\
\hline & Normal & Endometrial polyp & $\begin{array}{l}\text { Submucous } \\
\text { myoma }\end{array}$ & $\begin{array}{l}\text { Thin } \\
\text { endometrium }\end{array}$ & Synechiae \\
\hline Normal cavity (54) & 38 & 7 & 4 & 0 & 5 \\
\hline Endometrial polyp (1) & 0 & 1 & 0 & 0 & 0 \\
\hline Submucous myoma (0) & 0 & 0 & 0 & 0 & 0 \\
\hline Thin endometrium (4) & 0 & 0 & 0 & 1 & 3 \\
\hline Synechiae (0) & 0 & 0 & 0 & 0 & 0 \\
\hline Endometrial hyperplasia (1) & 0 & 0 & 1 & 0 & 0 \\
\hline Total $(n=60)$ & 38 & 8 & 5 & 1 & 8 \\
\hline
\end{tabular}

Table 5: Comparison of various accuracy parameters between present study and studies by other authors taking hysteroscopy as gold standard.

\begin{tabular}{|lllll|}
\hline TVS & $\begin{array}{c}\text { Sensitivity } \\
\%\end{array}$ & $\begin{array}{c}\text { Specificity } \\
\%\end{array}$ & $\begin{array}{c}\text { PPV } \\
\%\end{array}$ & $\begin{array}{c}\text { NPV } \\
\%\end{array}$ \\
\hline $\begin{array}{l}\text { Present } \\
\text { Study }\end{array}$ & 27.3 & 100 & 100 & 70.4 \\
\hline $\begin{array}{l}\text { Loverro } \\
\text { et al }\end{array}$ & 84.5 & 98.7 & 98 & 89.2 \\
\hline $\begin{array}{l}\text { Shalev } \\
\text { et al }^{13}\end{array}$ & 100 & 96.3 & 91.3 & 100 \\
\hline SIS & 36.4 & 100 & 100 & 73 \\
\hline $\begin{array}{l}\text { Present } \\
\text { Study }\end{array}$ & 83 & 96 & 91 \\
\hline $\begin{array}{l}\text { Bingol } \\
\text { et al }\end{array}$ & 98 & 94 & 95 & 98 \\
\hline $\begin{array}{l}\text { Ragni } \\
\text { et al }^{14}\end{array}$ & 98 & 100 & 100 & 88 \\
\hline $\begin{array}{l}\text { Alaetebi }^{15} \\
\text { et al }^{15}\end{array}$ & 88.46 & & & \\
\hline
\end{tabular}

\section{DISCUSSION}

Uterine cavity provides an environment for successful implantation and placentation. Evaluation of uterine cavity needs to be performed in basic evaluation of infertile women. Hysteroscopy, though accurate may not be possible in all settings besides being expensive. SIS, if found to be accurate can replace hysteroscopy in some of these settings, especially in developing countries. The present study evaluated the diagnostic accuracy of TVS and SIS for detection of uterine cavity abnormalities in patients of infertility taking hysteroscopy as the gold standard.

The incidence of uterine cavity abnormalities of $36.7 \%$ on hysteroscopy in patients of infertility in the present study is comparable to reported incidence of $30 \%$ and $34.88 \%$ by Pansky $M$ et al and Sahu et al respectively. ${ }^{7,8}$ However rate of abnormal findings in infertile patients who underwent diagnostic hysteroscopy was $57 \%$ in a study by Brown SE et al. ${ }^{9}$

Among the various abnormalities the incidence of intrauterine synechiae was high in the present study, being $36.36 \%(\mathrm{n}=8)$, while the evidence of endometrial polyps $36.36 \%(\mathrm{n}=8)$, submucous myoma $22.7 \%(\mathrm{n}=5)$ was comparable to other studies. In a study by Bingol et al the abnormalities detected in endometrial cavity were endometrial polyps $31.5 \%$, submucous myoma $29.5 \%$, endometrial hyperplasia in $23.7 \%$ and intrauterine adhesions in $12.4 \% .^{10}$ The incidence of abnormalities were polyp $35.7 \%$, sub mucosal myoma $12.5 \%$, Ashermanns syndrome $3.6 \%$, septate uterus $14.3 \%$ and endometrial hyperplasia $33.9 \%$ in the study by Devleta and Adem. ${ }^{11}$ The high incidence of intrauterine adhesion in the present study could be due to high prevalence of tuberculosis in a developing country like India. Three out of eight patients of intrauterine synechiae had history of intake of anti-tubercular treatment.

In the present study, on hysteroscopy, $36.73 \%(n=22)$ of women were found to have intra-cavity abnormalities. SIS picked intra-cavity abnormalities in eight out of 22 patients (sensitivity 36.4\%) and TVS detected abnormalities in only six patients (sensitivity $=27.3 \%$ ).

Sensitivity of TVS (27.3) for detecting abnormalities in the present study was low while specificity and PPV was comparable to other studies. ${ }^{12,13}$ SIS combined with TVS marginally improved the sensitivity $(36.4 \%)$ though still very low compared to other studies (Table 5). ${ }^{10,14,15}$ The overall low sensitivity of SIS in the present study can be partially explained by high incidence of intrauterine synechiae $(36.36 \%)$ and their low detection rate by SIS $(16.7 \%)$. In the present study out of eight patients with 
intrauterine synechiae five had mild lesions. Three out of the five patients with mild intrauterine synechiae were labelled as thin endometrium on TVS and normal on SIS. Mild synechiae especially near corneal regions are known to cause infertility and may not be detected by SIS as they do not distort the intrauterine cavity. ${ }^{16}$ In a retrospective study by Yucebilgin MS et al on 115 infertile there were two patients of intrauterine synechiae and both were not picked by SIS. Alborzi et al and Alaetabi et al showed sensitivity of $76.5 \%$ and $50 \%$ and specificity of $100 \%$ and $100 \%$ respectively for detection of intrauterine adhesions. ${ }^{15,18}$

The sensitivity, specificity, PPV and NPV of SIS for detection of submucous myoma in the present study were found to be $60 \%, 100 \%, 100 \%$, and $95 \%$ respectively which are comparable to the study by Rudra et al who showed a sensitivity of $88.2 \%$, specificity of $97.3 \%$, PPV $91.8 \%$. Grimbizis et al reported the sensitivity and specificity of SIS for submucous myoma as $80 \%$ and $91.5 \%$ respectively. ${ }^{19,20}$ The sensitivity of SIS for detection of endometrial polyp in the present study is $25 \%$, specificity is $100 \%$, PPV is $100 \%$ and NPV is $86.4 \%$. Rudra et al showed a sensitivity of $93.0 \%$, specificity of $94.1 \%$, PPV of $7.2 .9 \%$ and NPV of $98.1 \% .{ }^{19}$ Bingol et al in a similar study on 346 patients found sensitivity of $100 \%$ for detection of endometrial polyp which is quite high compared to the present study. ${ }^{10}$

\section{CONCLUSION}

The high incidence of intrauterine abnormalities in infertile patients in the present study suggests that a definite diagnostic tool is required for evaluation of uterine cavity. TVS, though an initial investigation for assessment of pelvic pathology in infertile patients is not an adequately sensitive test for uterine cavity abnormalities. There was marginal improvement in sensitivity on addition of SIS to TVS. Both TVS and SIS though less invasive, had high diagnostic failure for intrauterine adhesions. Preliminary data from this small case series suggests that SIS cannot be used as an alternative to hysteroscopy in patients of infertility. More clinical research in larger number of patients in varied settings is needed before the place of SIS in cases of infertility can be ascertained.

\section{ACKNOWLEDGEMENTS}

Authors would like to thank all the patients who participated in the study.

Funding: No funding sources

Conflict of interest: None declared

Ethical approval: The study was approved by the Institutional Ethics Committee

\section{REFERENCES}

1. Wallach EE. The uterine factor in infertility. Fertility Sterility. 1972;23:138-58.

2. Kessler I, Lancet M. Hysterography and hysteroscopy: a comparison. Fertility and Sterility. 1986;46:709-10.

3. Golan A, Eilat E, Ron-ER, Herman A, Soffer Y, Bukovsky Y. Hysteroscopy is superior to hysterosalpingography in infertility investigation. Acta Obstet Gynecol Scand. 1996;75:654-6.

4. Dudiac KM. Hysterosonography: a key to what is inside the uterus. Ultrasound Q. 2001;17:73-86.

5. Bartkowiak R, Kaminski P, Wielgos M, Bobrowska $\mathrm{K}$. The evaluation of uterine cavity with saline infusion sonohysterography and hysteroscopy in infertile patients. Neuro Endocrinology Letters. 2006;27:523-8.

6. Shushan A, Rojansky N. Should hysteroscopy be a part of the basic infertility workup? Hum Reprod. 1999;14:1923-4.

7. Pansky M, Feingold M, Sagi R, Herman A, Schneider D, Halperin R. Diagnostic hysteroscopy as a primary tool in a basic infertility workup. Journal of Society of Laproendoscopic Surgeons. 2006;10(2):231-5.

8. Sahu L, Tempe A, Gupta S. Hysteroscopic evaluation in infertile patients: a prospective study. Int J Reprod Contracept Obstet Gynecol. 2012;1(1):37-41.

9. Brown SE, Coddington CC, Schnor J, TonnerJP, Gibbons W, Oehninger S. Evaluation of outpatient hysteroscopy, saline infusion hysterosonography and hysterosalpingography in infertile women: a prospective, randomized study. Fertil Steril. 2000;74:1029-34.

10. Bingol B, Gunenc Z, Gedikbasi A, Guner H, Tasdemir S, Tiras B. Comparison of diagnostic accuracy of saline infusion sonohysterography. Transvaginal sonography and hysteroscopy of Obstet and Gynecol. 2011:31(1):54-8.

11. Balić D, Balić A. Office hysteroscopy, transvaginal ultrasound and endometrial histology: a comparison in infertile patients. Acta Medica Academia. 2011;40(1):34-8.

12. Loverro G, Nappi L, Vicino M, Carriero C, Vimercati A, Selvaggi L. Uterine cavity assessment in infertile women: comparison of transvaginal sonography and hysteroscopy. Eur J Obstet Gynecol Reprod Biol. 2001;100:67-71.

13. Shalev J, Meizner I, Bar-Hava I, Dicker D, Mashiach $\mathrm{R}$, Rafael ZB. Predictive value of transvaginal sonography performed before routine diagnostic hysteroscopy for evaluation of infertility. Fertility Sterility. 2000;73:412-7.

14. Ragni G, Diaferia D, Vagtti W, Colombo M, Arnoldi M, Crosignani PG. Effectiveness of sonohysterography in infertile patient work up: a comparison with transvaginal ultrasonography and hysteroscopy. Gynecol Obstet Invest. 2005;59:184-8. 
15. Alaetebi F, Fayek W. Sonohysterography is a reliable and accurate method for investigating uterine factor infertility. Evidence Based Women's Health Journal. 2011;1:100-6.

16. Valle RF, Sciarra JJ. Intrauterine adhesions: hysteroscopic diagnosis, classification, treatment, and reproductive outcome. Am J Obstet Gynecol. 1988;158:1459-70.

17. Yucebilgin MS, Aktan E, Bozkurt K, Kazandi M, Akercan F, Mgoyi L, et al. Comparison of hydrosonography and diagnostic hysteroscopy in the evaluation of infertile patients. Clinical and Experimental Obstetrics and Gynecology. 2004;31:55-8.
18. Alborzi S, Dehbashi S, Khodaee R. Sonohysterosalpingographic screen for infertile patients. Int J Gynaecol Obstet. 2003;82:57-62.

19. Rudra B, Duggal BS, Bhardwaj D. Prospective study of saline infusion sonography and office hysteroscopy. Medical Journal Armed Forces India. 2009;65:332-5.

20. Grimbis GF, Tsolakidis D, Mikos T, Anagnostou E, Asimakopoulos E, Stamatopoulos P, et al. A prospective comparison of transvaginal ultrasound, saline infusion Sonohysterography and diagnostic hysteroscopy in the evaluation of endometrial pathology. Fertil Steril . 2010;94:2720-5.

Cite this article as: Sitimani A, Chawla I, Vohra P. Saline infusion sonography in evaluation of uterine cavity abnormalities in infertility: a comparative study. Int J Reprod Contracept Obstet Gynecol 2016;5:2995-3000. 